P0157

\title{
EXAMINATION OF THE APPLICATION RANGE OF THE AVERAGE LUMINANCE FOR ESTIMATING SCENE BRIGHTNESS
}

\author{
Nozomu Yoshizawa et al.
}

DOI 10.25039/x46.2019.PO157

from

CIE x046:2019

Proceedings

of the

29th CIE SESSION

Washington D.C., USA, June 14 - 22, 2019

(DOI 10.25039/x46.2019)

The paper has been presented at the 29th CIE Session, Washington D.C., USA, June 14-22, 2019. It has not been peer-reviewed by CIE.

(C) CIE 2019

All rights reserved. Unless otherwise specified, no part of this publication may be reproduced or utilized in any form or by any means, electronic or mechanical, including photocopying and microfilm, without permission in writing from CIE Central Bureau at the address below. Any mention of organizations or products does not imply endorsement by the CIE.

This paper is made available open access for individual use. However, in all other cases all rights are reserved unless explicit permission is sought from and given by the $\mathrm{CIE}$.

CIE Central Bureau

Babenbergerstrasse 9

A-1010 Vienna

Austria

Tel.: +43 17143187

e-mail: ciecb@cie.co.at

www.cie.co.at 


\title{
EXAMINATION OF THE APPLICATION RANGE OF THE AVERAGE LUMINANCE FOR ESTIMATING SCENE BRIGHTNESS
}

\author{
Yoshizawa, N. ${ }^{1}$, Numaziri, M. ${ }^{1}$, Kato, M. ${ }^{2}$, Yamaguchi, H. ${ }^{3}$, Hara, N. ${ }^{4}$, Iwai, W. ${ }^{5}$, Suzuki, N. ${ }^{6}$, Sakata, K. ${ }^{7}$ \\ ${ }^{1}$ Tokyo University of Science, Chiba, JAPAN, ${ }^{2}$ Nihon University, Chiba, JAPAN, ${ }^{3}$ National Institute \\ for Land and Infrastructure Management, Tsukuba, JAPAN, ${ }^{4}$ Kansai University, Osaka, JAPAN, \\ ${ }^{5}$ Panasonic, Osaka, JAPAN, ${ }^{6}$ Endo Lighting, Tokyo, JAPAN, ${ }^{7}$ Kajima, Tokyo, JAPAN,
}

yosizawa@rs.noda.tus.ac.jp

DOI 10.25039/x46.2019.PO157

\begin{abstract}
Spatial brightness is one of the useful metrics for balancing energy efficiency and high quality of light environment. Based on the result of a subjective experiment on the scene/spatial brightness, the application range of the average luminance for estimating scene brightness for general open offices was examined. The results showed that, in the basically uniform light environment in offices, arithmetic average luminance over 180-degree field of view and arithmetic average luminance of a ceiling surface could well explain the scene brightness.
\end{abstract}

Keywords: Scene brightness, Spatial brightness, Arithmetic average luminance

\section{Motivation and purposes}

As it is getting more important to strike a balance between energy efficiency and the high quality of light environment, the necessity of luminance-based design has been gradually recognized in the field of architectural lighting design, and the brightness design has been also brought back into the spotlight recently. Current CIE S 008/E-2001 (ISO 8995-1:2002/Cor 1:2005) clearly mentions the importance of luminance distribution for satisfying visual comfort, visual performance, etc., and the Europe lighting standard (EN 12464-1:2011 Light and lightingLighting of work places-Part 1: Indoor work places) says "it is highly desirable to have bright interior surfaces particularly the walls and ceiling", and shows the maintained illuminances on the major surfaces. Architectural Institute of Japan published new standards for lighting environment (AIJES-L0002-2016) in 2016, and minimal average luminance values on the walls and ceilings are recommended to secure the scene/spatial brightness in buildings. Some manufacturers in Japan proposed their original indexes for evaluating the scene/spatial brightness and have already started to use them in their pre/post evaluation process of the lighting design.

Now the revision tasks for CIE S 008/E-2001 (ISO 8995-1:2002/Cor 1:2005) will start in 2019, thus our questions are as follows: 1) To secure the brightness in buildings, which parameter is better as the quantifiable value in lighting standards, illuminance or luminance? 2) Which parameter is better for securing brightness in the space, illuminance/luminance on the surfaces or scene/spatial brightness indexes? 3) To what extent the simple average luminance can be used for estimating the scene/spatial brightness?

A working group for brightness has been organized in Architectural Institute of Japan (AIJ), and in this paper, we will focus on the verification about 2) and 3), based on the result of a subjective experiment on the scene/spatial brightness conducted by the WG members.

\section{Brightness, scene brightness and spatial brightness}

A working group for brightness in AlJ has proposed to distinguish the terms: brightness, scene brightness and spatial brightness. As shown in Figure1, "brightness" indicates the brightness of a small spot on a certain object, "scene brightness" means the brightness over a certain area cut off from the field of view, and "spatial brightness" is the overall brightness inside the whole space evaluated by looking around the 360-degree field of view. These terms should be more discussed in the academic field, but, in this paper, we will use the term "scene brightness" to 
describe the brightness over the area in front of the observers and report the experimental results on that.

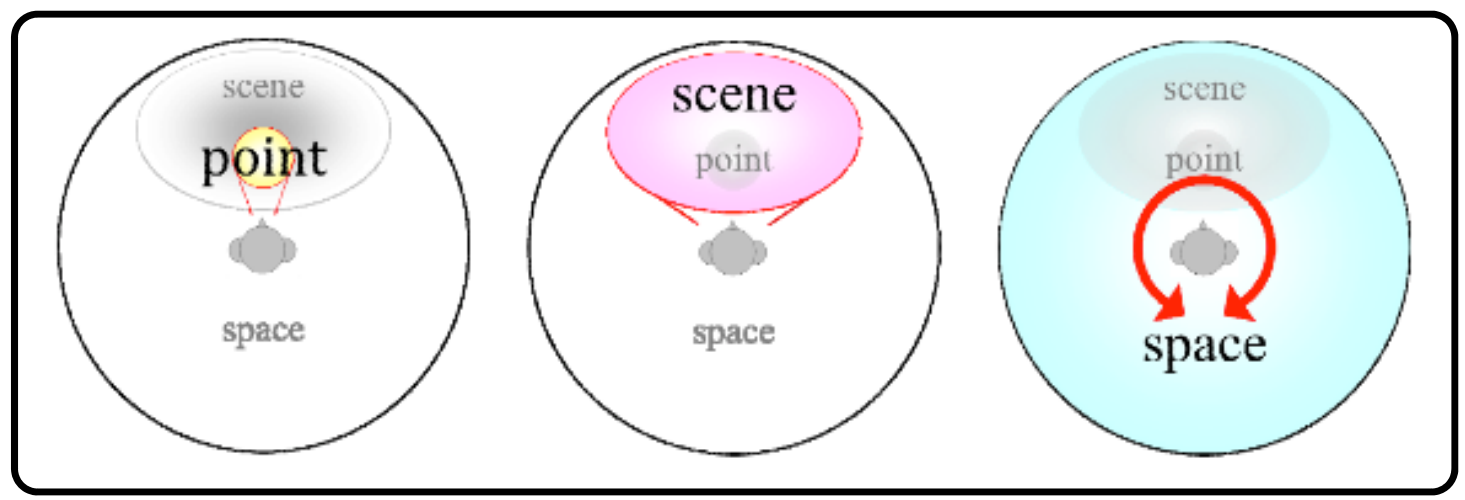

Figure 1 - Brightness(left), scene brightness(middle) and spatial brightness(right)

\section{Experimental outlines}

\subsection{Experimental space}

The experiment was conducted at the mock office whose room size was $12.3 \mathrm{~m}$ in Width, $5.6 \mathrm{~m}$ in Depth and $4.0 \mathrm{~m}$ in Height. Two kinds of size for the experimental space were prepared for the experiment: one is the whole room (Large) and the other is the half of it (Small). The interior surface reflectance was $85.4 \%$ for the ceiling, $82.1 \%$ (high) $/ 20.7 \%$ (low) for the walls and $20.7 \%$ for the floor.

\subsection{Lighting conditions}

Four kinds of luminaires were used in the experiment: ceiling lights, downlights, wall washer lights and pendant lights. Figure2 shows the pictures inside the experiment space. All the luminaires were installed at regular spacings. The correlated colour temperature was $4000 \mathrm{~K}$.

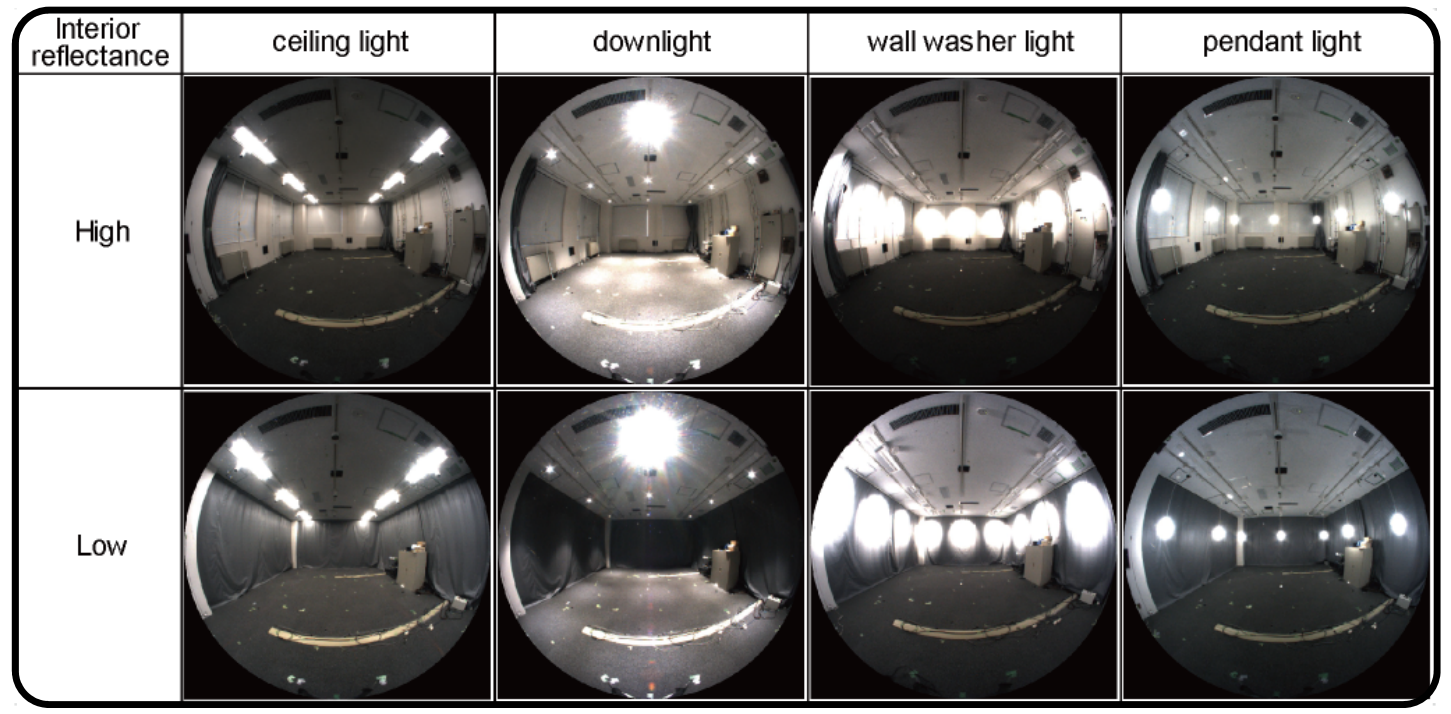

Figure 2 - Inside the experiment space (Space size: Large)

The outputs of luminaires were controlled to match the arithmetic mean luminance over the 180-degree field of view from the viewpoint at the centre of the experimental room to the target values described in Table1. Basically, three levels of the arithmetic mean luminance were chosen for each lighting condition among four settings: $6,17,50,100 \mathrm{~cd} / \mathrm{m}^{2}$. Luminance distribution in the space was measured using a CCD camera (TXG13c, Baumer) and a fisheye lens (FE185C046HA01, FUJINON). 


\subsection{Evaluation methods}

First, the subject adapted to the light environment with ceiling lights on in 20 seconds, whose arithmetic average luminance was the same as the lighting condition to be evaluated later. Secondly, after the lighting condition was presented, the subject observed the space at the centre of the space in 20 seconds and memorized the scene brightness. Thirdly, the subject adjusted the brightness in a reference box to the same as the memorized brightness in the experimental space. Finally, the subject moved back to the centre of the experimental space, and evaluated the appropriateness of the brightness as the ambient lighting for offices in 7point scales (too dark - appropriate - too bright). The lighting conditions were presented to each subject basically at random order, except that interior reflectance and the size of the experimental space were treated as block factors. 6 female and 14 male aged 20's participated the experiment.

For the reference box, a dome-shaped box whose inner luminance is almost uniform was prepared, and subjects adjusted its luminance by themselves. Correlated colour temperature of the lighting was $4000 \mathrm{~K}$.

Table 1 - Setting values of Arithmetic mean luminance

\begin{tabular}{|c|c|c|c|c|c|c|}
\hline & \multirow{2}{*}{$\begin{array}{l}\text { Space } \\
\text { size }\end{array}$} & \multirow{2}{*}{$\begin{array}{l}\text { Interior } \\
\text { reflectance }\end{array}$} & \multicolumn{4}{|c|}{ Arithmetic mean luminance $\left(\mathrm{cd} / \mathrm{m}^{2}\right)$} \\
\hline & & & 6 & 17 & 50 & 100 \\
\hline \multirow{4}{*}{$\begin{array}{l}\text { Ceiling } \\
\text { Light }\end{array}$} & \multirow{2}{*}{ Large } & High & & 0 & 0 & 0 \\
\hline & & Low & & $\bullet$ & $\bullet$ & 0 \\
\hline & \multirow{2}{*}{ Small } & High & & 0 & 0 & 0 \\
\hline & & Low & & 0 & 0 & 0 \\
\hline \multirow{4}{*}{$\begin{array}{l}\text { Down } \\
\text { Light }\end{array}$} & \multirow{2}{*}{ Large } & High & 0 & 0 & 43 & \\
\hline & & Low & 9 & 0 & 0 & \\
\hline & \multirow{2}{*}{ Small } & High & 0 & 0 & 27 & \\
\hline & & Low & 0 & 0 & & \\
\hline \multirow{4}{*}{$\begin{array}{l}\text { Wall } \\
\text { Washer } \\
\text { LIght }\end{array}$} & \multirow{2}{*}{ Large } & High & & 0 & 0 & \\
\hline & & Low & 0 & 0 & 27 & \\
\hline & \multirow{2}{*}{ Small } & High & 0 & 0 & 0 & \\
\hline & & Low & - & 0 & 25 & \\
\hline \multirow{4}{*}{$\begin{array}{l}\text { Pendant } \\
\text { Light }\end{array}$} & \multirow{2}{*}{ Large } & High & - & 0 & 23 & \\
\hline & & Low & 0 & 0 & & \\
\hline & \multirow{2}{*}{ Small } & High & 0 & 0 & 25 & \\
\hline & & Low & 0 & 16 & & \\
\hline
\end{tabular}

\section{Experimental Results}

The high luminance around the downlights exceeded the measurement limit for the CCD camera, and could not be correctly measured, therefore, the results as to downlights in the following analyses will be just presented for the reference. 


\subsection{Arithmetic average luminance over the 180-degree field of view}

Figure 3 shows the results of arithmetic average luminance over the 180-degree field of view. In these graphs, $x$-axis represents the average luminance of the space and $y$-axis represents the average luminance in the reference dome adjusted by subjects to the same as the memorized brightness in the experimental space. If the plot is on the line of 45-degree angle, it indicates that both the average luminance values are equal. The results show that, except for the lighting conditions with downlight, the 45-degree angle lines are located inside the range of $95 \%$ confidence interval, and the average luminance values of the experimental space and the reference dome are almost equal. There is a tendency that the brightness of light environment with ceiling lights was evaluated a bit lower than that with wall washer lights and pendant lights. It can be conjectured that relatively high luminance on vertical walls in the latter environment brought this result.

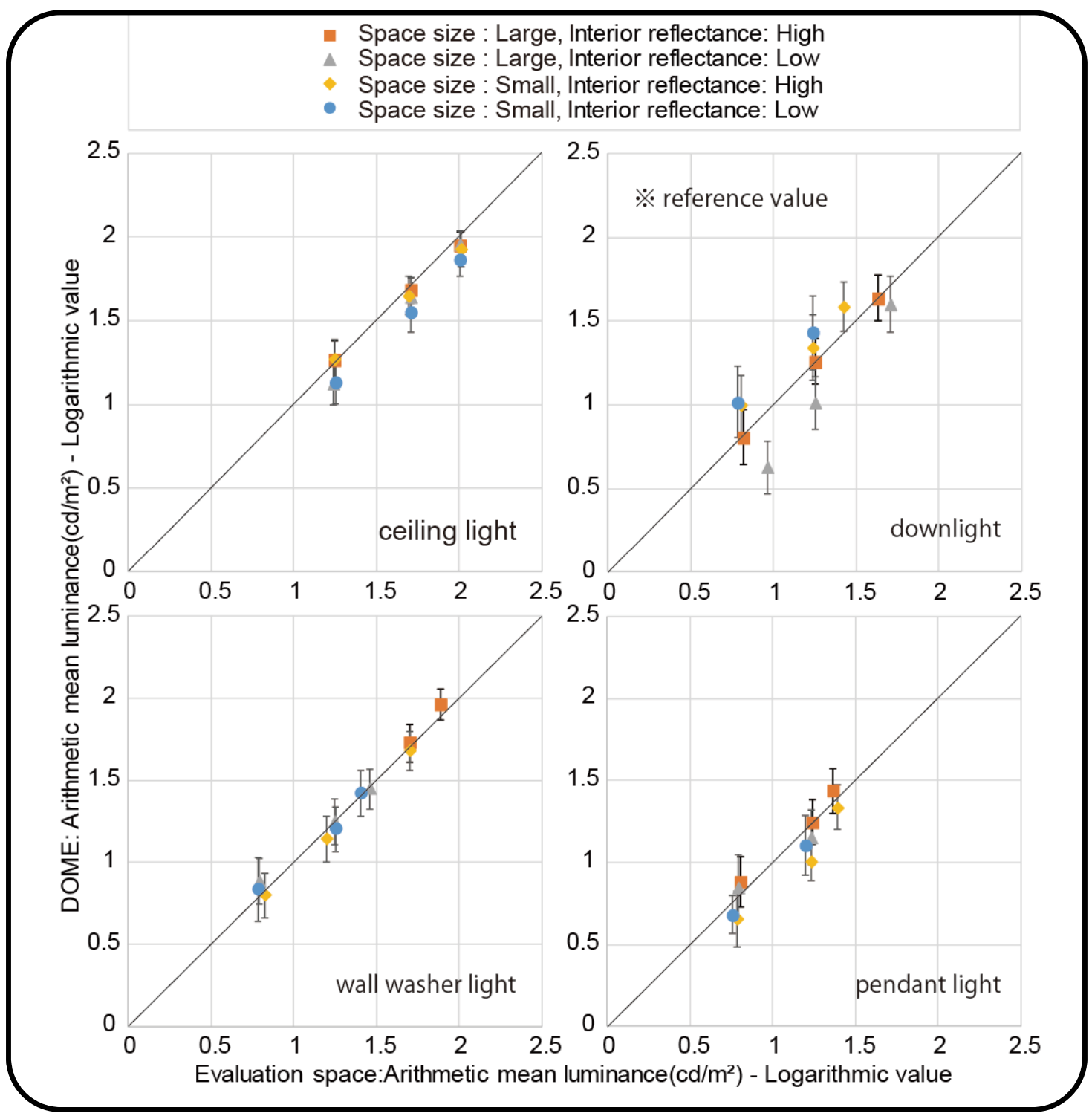

Figure 3 - Relation between the luminance of the experimental space over the 180-degree field of view and the adjusted luminance in the reference dome

\subsection{Arithmetic average luminance of the ceiling and the walls}

AIJES-L0002-2016 prescribes minimum values of arithmetic average luminance on walls and ceiling. This average luminance does not include light sources. Figure4 shows the experimental results of the arithmetic average luminance of the walls and the ceiling. In these graphs, $x$-axis represents the average luminance of the walls/ceiling and $y$-axis represents the average luminance in the reference dome adjusted by subjects to the same as the memorized brightness 
in the experimental space. There is a tendency that all the plots are in the left side of the line of 45-degree angle for the ceiling luminance (Figure4:Left), while the fluctuation is high for the wall luminance (Figure4:Right).

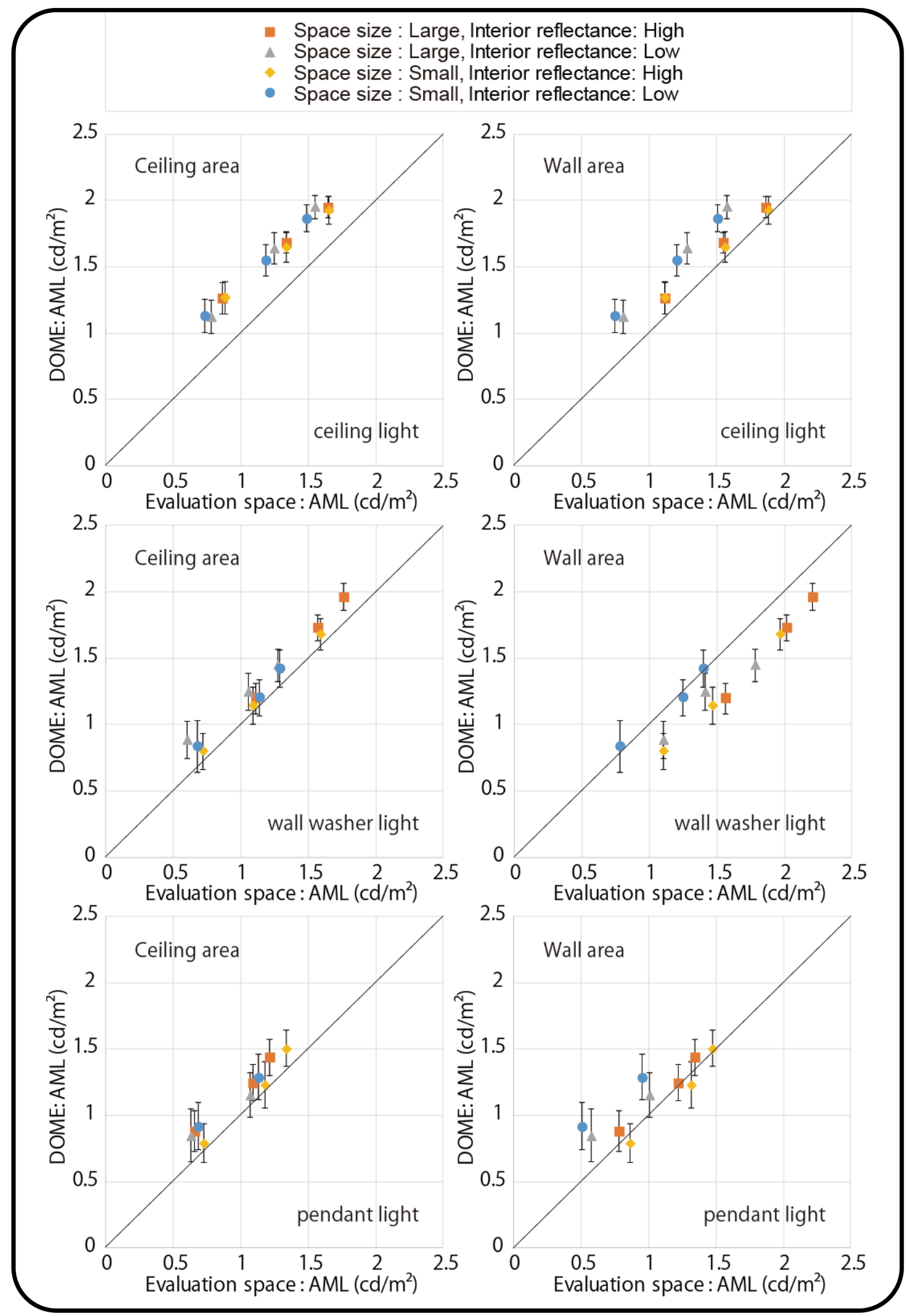

Figure 4 - Relation between the luminance on the ceiling/walls in the experimental space and the adjusted luminance in the reference dome 


\subsection{Comparison among 180-degree field of view, a ceiling and walls}

For the metrics to estimate scene/spatial brightness in the lighting standards, it would be required that this index is robust among various light settings. Therefore, to compare the levels of differences among different luminaires, from the graphs in Figure3\&4, the intercept(a) was obtained from the regression equation: $y=x+a$ for all the luminaire settings except downlights, and the difference between maximum and minimum was calculated. As shown in Figure5, the difference was the smallest in the arithmetic average luminance over the 180-degree field of view, and the largest in that of walls. The robustness as the metrics of the arithmetic average luminance of the ceiling (excluding luminaires) is close to the luminance over the whole field of view.

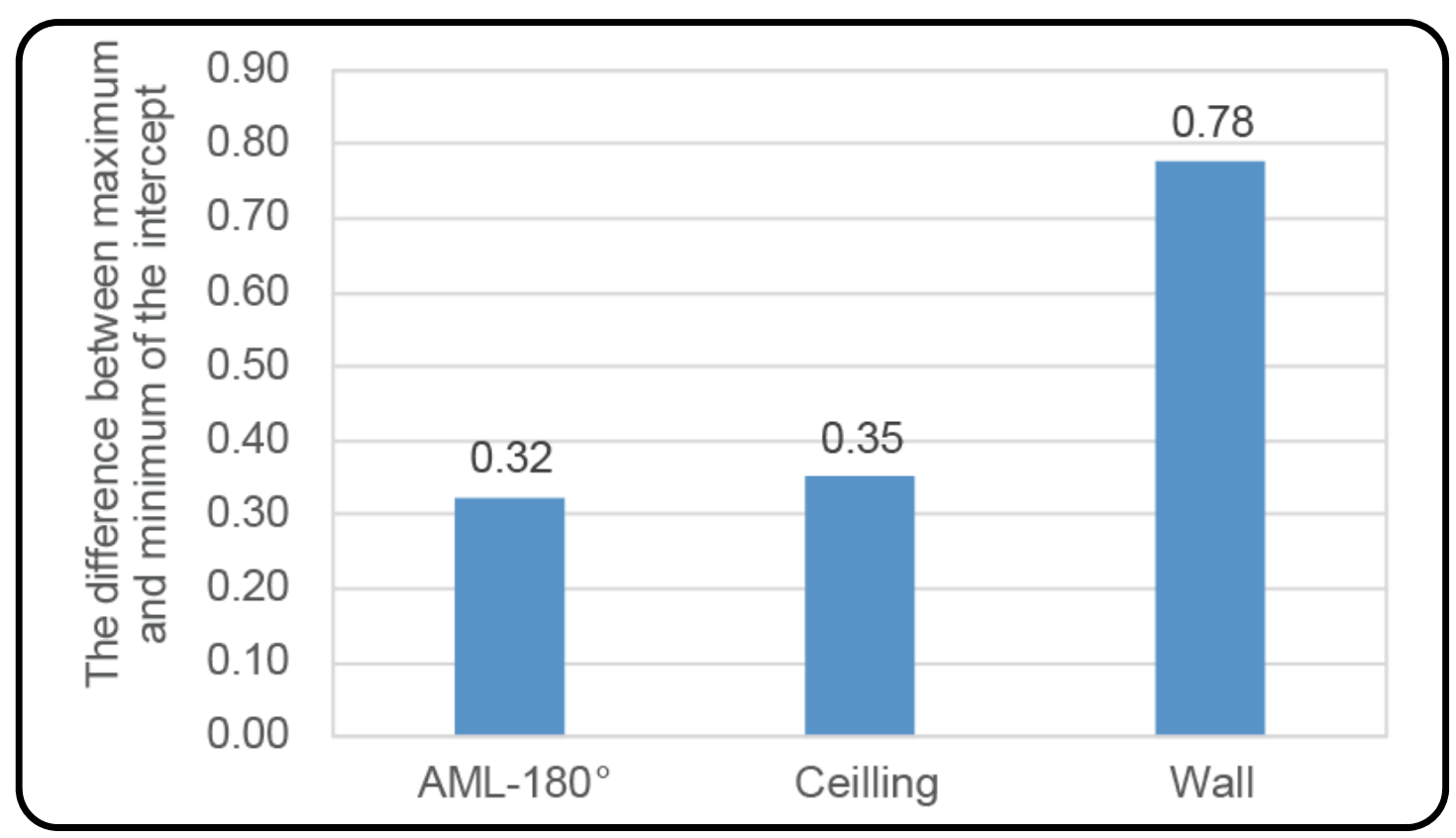

Figure 5 - The difference between maximum and minimum of the intercept

\section{Conclusion and Future works}

Based on the result of a subjective experiment on the scene/spatial brightness, the application range of the average luminance for estimating scene brightness was examined. The results showed that, in the basically uniform light environment in offices, arithmetic average luminance over 180-degree field of view and arithmetic average luminance of a ceiling surface could well explain the scene brightness. In future works, the lighting conditions with downlights should be re-examined, and clarify the applicable range of the arithmetic average luminance more precisely. The required levels of the scene/spatial brightness for the working spaces, etc. should be also investigated to use these metrics in lighting standards.

\section{References}

EUROPEAN COMMITTEE FOR STANDARDIZATION 2011. EN 12464-1:2011. Light and lighting-Lighting of work places-Part 1: Indoor work places;

Architectural Institute of Japan. 2016. Architectural Institute of Japan Environmental Standards AIJESL0002-2016 Standards for Lighting Environment. (in Japanese)

Iwai, W., Iguchi, M. 2008. New lighting evaluation techniques for comfortable lighting spaces using sensation-of-room-brightness index "Feu" (in Japanese). MATSUSHITA Technical Journal, 53(2), 132-134. 